\title{
POLÍTICA DE INDEXAÇÃO NA CATALOGAÇÃO DE ASSUNTO EM BIBLIOTECAS UNIVERSITÁRIAS: A VISÃO SOCIOCOGNITIVA DA ATUAÇÃO PROFISSIONAL COM PROTOCOLO VERBAL
}

\author{
Milena Polsinelli Rubi \\ Mariângela Spotti Lopes Fujita
}

\section{Resumo:}

A política de indexação deve fundamentar-se em uma filosofia que reflita os objetivos do sistema. Um dos aspectos concernentes à política de indexação diz respeito à conversão retrospectiva de dados para formação de catálogos coletivos. Nosso objetivo é identificar e analisar os elementos para o estabelecimento de uma política de indexação que seja norteadora dos procedimentos de indexação realizados em bibliotecas universitárias a partir da visão sociocognitiva dos bibliotecários diretores, catalogadores, de referências, docentes e discentes. Como metodologia, utilizamos questionário de diagnóstico organizacional e a técnica de coleta de dados introspectiva e qualitativa denominada Protocolo Verbal. Os resultados demonstraram que a política de indexação deve servir como subsídio para a organização do conhecimento no catálogo, atuando como guia para o bibliotecário no momento da determinação dos assuntos dos documentos descritos nos registros. Concluímos que a indexação só será realizada na biblioteca universitária durante o tratamento da informação documentária por meio de decisão política bem determinada.

\section{Palavras-chave:}

Política de indexação. Indexação. Catalogação de assunto. Catalogação cooperativa. Protocolo Verbal. Biblioteca universitária

\section{INDEXING POLICY IN SUBJECT CATALOGING IN UNIVERSITY LIBRARIES: A SOCIAL-COGNITIVE VIEW OF PROFESSIONAL EXPERIENCE WITH THE VERBAL PROTOCOL}

\begin{abstract}
:
The indexing policy must be represented by means of a philosophy that reflects the system's aims. One of the aspects concerning the indexing policy is relating to the data retrospective conversion. The general aim is to discuss and make a profound study on indexing policy guidelines and to analyze the elements to set up an indexing policy, that should direct the indexing procedures carried out in university libraries using the methodology of verbal protocol. The results demonstrate that the indexing policy serves as a support for the knowledge organization in the catalog, acting as a guide for the librarian when determining the subjects of the documents described in the records. It is concluded that the indexing only will be carried out in the university library during the documentary information treatment by means of a well determined policy.
\end{abstract}

Keywords:

Indexing policy. Indexing. Subject cataloging. Cooperative cataloging. Verbal protocol. University libraries 


\section{INTRODUÇÃO}

A automação propiciou avanços na cooperação entre bibliotecas e, conseqüentemente, na catalogação cooperativa, agilizando o processo e diminuindo o tempo de serviço com o aproveitamento de registros bibliográficos copiados de outras bases de dados.

Dessa forma, os catálogos coletivos de bibliotecas são construídos a partir de registros oriundos de outras instituições com características, objetivos e usuários diversos, mediante um processo de conversão retrospectiva. Sabemos que a descrição das características físicas de um mesmo documento, cujo registro foi convertido para o catálogo, não apresentará variações de uma instituição para outra, porém, a representação dos assuntos desses documentos precisará ser alterada tendo em vista as características, os objetivos e os usuários de cada biblioteca.

Entendemos que, devido à economia de recursos humanos e financeiros, não se pode pensar em automação de bibliotecas e na migração de um catálogo pré-existente para um catálogo on-line sem a utilização do processo de conversão retrospectiva de registros bibliográficos e da catalogação cooperativa automatizada que, por meio de um formato bibliográfico, proporcione o intercâmbio de registros de forma padronizada.

A cooperação entre bibliotecas para construção de catálogos trouxe um importante avanço para a área em relação à otimização do processo de catalogação, no entanto, o processo de identificação de assunto por meio da análise foi simplificado, reduzindo-o a uma simples operação de “cópia”, contemplando dessa forma somente a questão da “forma” na catalogação, deixando de lado o “conteúdo”.

Essa simplificação da catalogação de assunto, questão prática do dia-a-dia do bibliotecário, remete-nos a uma questão teórica e conceitual muito discutida, ainda que não sedimentada, na área de Biblioteconomia: a conceituação de indexação e catalogação de assunto.

Essas diferenças repercutem no aspecto citado anteriormente sobre a simplificação do processo de catalogação de assunto durante o trabalho de construção dos catálogos. Ou seja, o bibliotecário que faz a catalogação cooperativa, copia o registro de outra 
biblioteca e o incorpora ao seu catálogo sem fazer, no campo de assunto, as modificações necessárias que atendam à sua comunidade usuária, trabalhando, dessa maneira, somente a forma do documento, sem se preocupar com o conteúdo. Esse procedimento acarretará conseqüências diretas para essa comunidade já que a indexação da biblioteca não corresponderá ao seu perfil, comprometendo a recuperação da informação.

Podemos considerar que essa situação talvez ocorra por não haver percepção por parte do bibliotecário sobre o processo de indexação que ele realiza durante a catalogação, uma vez que existe um campo para determinação do assunto do documento.

Este trabalho, oriundo de tese de doutorado (RUBI, 2008), tem por objetivo contribuir identificar e analisar os elementos para o estabelecimento de uma política de indexação que seja norteadora dos procedimentos de indexação realizados em bibliotecas universitárias a partir da visão sociocognitiva dos bibliotecários diretores, catalogadores, de referências, docentes e discentes, utilizando como metodologia o protocolo verbal em grupo e individual. Para tanto, apresentamos os catálogos coletivos e o processo de conversão retrospectiva para sua construção, no contexto da biblioteca universitária, e os elementos de política de indexação que contribuirão para a construção desses catálogos, igualmente abordamos as diferenças conceituais entre indexação e catalogação de assunto. A seguir, descrevemos o processo de conversão retrospectiva para a construção de catálogos coletivos e as contribuições da política de indexação para esse processo. Quanto à metodologia, apresentamos a técnica introspectiva de coleta de dados qualitativos - o protocolo verbal - utilizado para evidenciar a visão sociocognitiva dos profissionais bibliotecários e usuários das bibliotecas universitárias. A seguir, discutimos as análises dos resultados obtidos e apresentamos nossas considerações finais.

\section{PERSPECTIVAS TEÓRICAS E METOdOLÓGICAS DA INDEXAÇÃo E DA CATALOGAÇÃO DE ASSUNTO}

A fim de contextualizar a política de indexação na catalogação de assunto, apresentamos as divergências teóricas entre a indexação e a catalogação de assunto no contexto do tratamento temático da informação.

(c) Revista Digital de Biblioteconomia e Ciência da Informação,Campinas, v.7, n. 2, p. 118-150, jan.jun. 2010- ISSN: 1678-765X. 
O tratamento documentário é a etapa intermediária inserida em um conjunto de operações denominado ciclo documentário (ou cadeia documental).

Para Shaw (1957) o ciclo documentário envolve a identificação, a gravação, a organização, o armazenamento, a recuperação, a conversão em formas mais úteis e a disseminação do conteúdo intelectual de materiais impressos e outros registrados. O referido autor afirma que o ciclo documentário completo é realizado pelos serviços especializados de documentação, voltados para necessidades específicas de usuários especialistas. As bibliotecas, de maneira geral, dedicam-se apenas a uma parte desse ciclo, entre a gravação e a recuperação da informação.

Além do tratamento documentário, enquanto etapa intermediária, Guinchat e Menou (1994) afirmam que o ciclo documentário comporta inicialmente a coleta de documentos e a difusão da informação ao final.

Para Fujita (2003), a organização da informação compreende as atividades e operações do tratamento da informação, envolvendo para isso o conhecimento teórico e metodológico disponível tanto para o tratamento descritivo do suporte material da informação quanto para o tratamento temático do conteúdo da informação.

O tratamento descritivo refere-se propriamente à catalogação, ou seja, à representação descritiva da forma física do documento (autor, título, edição, casa publicadora, data, número de páginas etc.). Já, o tratamento temático, em bibliotecas, diz respeito ao assunto tratado no documento, ou seja, compreende a análise documentária como área teórica e metodológica que abrange as atividades de classificação, elaboração de resumos, indexação e catalogação de assunto, considerando as diferentes finalidades de recuperação da informação.

Esta dicotomia que se apresenta no tratamento da informação é explicada, de um lado, pelo desenvolvimento teórico e metodológico distinto alcançado pelas duas áreas e, de outro, pela diferença existente entre os aspectos da informação - o material e o conteúdo - que exigem tratamento diferenciado. (FUJITA, 2003).

Neste trabalho, nosso foco é o tratamento temático, especialmente a indexação e a catalogação de assunto a partir de um quadro conceitual que delineamos a seguir.

(c) Revista Digital de Biblioteconomia e Ciência da Informação,Campinas, v.7, n. 2, p. 118-150, jan./jun. 2010- ISSN: 1678-765X. 
Pinto Molina (1993) e Silva e Fujita (2004) apresentam de maneira sintetizada um histórico da indexação, chamando a atenção para sua utilização desde os tempos das tábuas de argila (séc. II a.C.), em que foram encontradas formas de representação condensada que davam acesso aos conteúdos dos documentos, até o grande desenvolvimento da indexação que se dá ao final do século XIX com o aumento de publicações periódicas e da literatura técnico-científica de modo geral.

Desde então, estudos vêm sendo desenvolvidos acerca da teoria da indexação, sua natureza, procedimentos e estruturas e características de seu produto final, o índice.

O termo indexação (indexing) remonta à corrente teórica inglesa e, de acordo com os “Princípios de indexação” do World Information System for Science and Technology ${ }^{1}$ (UNISIST, 1981, p. 84) é “[...] a ação de descrever e identificar um documento de acordo com seu assunto.”

A publicação do UNISIST originou a primeira norma a esse respeito publicada em 1985 pela International Standardization for Organization (ISO), sob número 5963, com o título "Documentation - methods for examining documents, determining their subjects, and selecting indexing terms".

Em 1992, a Associação Brasileira de Normas Técnicas (ABNT) publicou a tradução dessa mesma norma, sob número 12676, intitulada "Métodos para análise de documentos - determinação de seus assuntos e seleção de termos de indexação”. Nessa Norma, a indexação é definida como “Ato de identificar e descrever o conteúdo de um documento com termos representativos dos seus assuntos e que constituem uma linguagem de indexação.” (ASSOCIAÇÃO BRASILEIRA DE NORMAS TÉCNICAS, 1992, p. 2).

Para Chaumier (1988, p. 63) “[...] a indexação é a parte mais importante da análise documentária. Conseqüentemente é ela que condiciona o valor de um sistema documentário.” O termo indexação é definido por Van Slype (1991) como a operação que consiste em enumerar os conceitos sobre os quais trata um documento e

\footnotetext{
${ }^{1}$ Sistema internacional vinculado à Organização das Nações Unidas para a Educação, a Ciência e a Cultura (UNESCO) e conhecido pela sigla UNISIST.
}

(C) Revista Digital de Biblioteconomia e Ciência da Informação,Campinas, v.7, n. 2, p. 118-150, jan./jun. 2010- ISSN: 1678-765X. 
representá-los por meio de uma linguagem combinatória - lista de descritores livres, lista de autoridades e o thesaurus de descritores - tendo como finalidade a busca documental que será realizada a partir dos índices ou dos catálogos.

De acordo com Pinto Molina (1993, p. 208), a indexação “[...] é a técnica de caracterizar o conteúdo de um documento (...) retendo as idéias mais representativas para vinculá-las a termos de indexação adequados.”

Lancaster (2004, p. 1) explica que “[...] os processos de indexação identificam o assunto que trata o documento [...]” e eles implicam “[...] a preparação de uma representação do conteúdo temático dos documentos.” (LANCASTER, 2004, p. 6, grifo do autor).

Para Robredo (2005, p. 165) “A indexação consiste em indicar o conteúdo temático de uma unidade de informação, mediante a atribuição de um ou mais termos (ou códigos) ao documento, de forma a caracterizá-lo de forma unívoca.”

Consideramos, portanto, que a indexação diz respeito à identificação do conteúdo do documento, por meio do processo de análise de assunto, e à sua representação através de conceitos, que por sua vez, serão representados ou traduzidos em termos advindos de uma linguagem documentária, com vistas à intermediação entre o documento e o usuário no momento da recuperação da informação, seja em índices, catálogos ou bases de dados.

Tendo em vista as considerações conceituais sobre indexação acima referidas, torna-se importante ressaltar a questão da catalogação de assunto para, a seguir, tratar das divergências conceituais entre ambas.

O uso do termo “catalogação de assunto" (subject cataloguing) traz a influência norte-americana e remonta a Cutter (1904) que atribui sua obra Rules for a dictionary catalog, o objetivo de estabelecer regras para a formação de cabeçalhos alfabéticos de assuntos, que formariam catálogos alfabéticos de assunto. 
Acreditamos que os conceitos dessa obra, que constituem os fundamentos para a teoria e prática da catalogação de assunto americana, também influenciaram Ranganathan (1931) na elaboração das 5 leis da Biblioteconomia (Livros são para uso; Para cada leitor, seu livro; para cada livro, seu leitor; Poupe o tempo do leitor; A biblioteca é uma organização em crescimento) principalmente no que diz respeito à segunda, terceira e quarta leis.

Fiúza (1985, p. 257) define a catalogação de assunto como “[...] a disciplina ou conjunto de disciplinas que tratam da representação, nos catálogos de bibliotecas, dos assuntos contidos no acervo.”

Para Cutter (1904), os objetivos da catalogação de assunto eram: permitir ao usuário do catálogo encontrar um documento particular do qual o assunto é conhecido; encontrar outros documentos sobre o mesmo assunto ou sobre assuntos relacionados; dar assistência ao usuário na seleção de registros recuperados, o documento mais adequado às suas necessidades informacionais.

De acordo com Silva e Fujita (2004) o termo catalogação de assuntos caracteriza-se pela atribuição de cabeçalhos de assunto para a representação do conteúdo total dos documentos em catálogos de biblioteca, cuja está ligada à construção dos catálogos de assunto das bibliotecas.

Milstead (1983) reconhece que conceitualmente a catalogação de assunto e a indexação são a mesma atividade, mas são tratadas como se fossem diferentes, principalmente do ponto de vista prático atual, sendo que ambas podem contribuir uma com outra.

Sobre isso, Fiúza (1985, p. 258, grifo do autor) afirma que “A indexação é considerada como uma disciplina superior que se preocupa com os sistemas de recuperação de informação, entre os quais se cita en passant o pobre catálogo manual.”

Fujita (2003, p. 75) acredita que a catalogação de assunto em bibliotecas deriva da atividade de classificação, uma vez que

Os índices outrora existentes em sistemas de recuperação da informação, tais como os antigos catálogos de fichas de bibliotecas, foram considerados dentro de uma perspectiva classificatória, porque

(C) Revista Digital de Biblioteconomia e Ciência da Informação,Campinas, v.7, n. 2, p. 118-150, jan./jun. 2010- ISSN: 1678-765X. 
os chamados cabeçalhos de assunto eram compostos sob influência da terminologia classificatória e não do texto e seu conteúdo.

Lancaster (2004) entende que a diferença presente na literatura da área sobre as expressões catalogação de assuntos, indexação e classificação são inexpressivas e causadoras de confusão.

Catalogação de assuntos refere-se comumente à atribuição de cabeçalhos de assuntos para representar o conteúdo total de itens bibliográficos inteiros (livros, relatórios, periódicos, etc.) no catálogo das bibliotecas. Indexação de assuntos é uma expressão usada de modo mais impreciso; refere-se à representação do conteúdo temático de partes de itens bibliográficos inteiros, como é o caso de um índice no final de um livro. [...] O fato é que a classificação, em seu sentido mais amplo, permeia todas as atividades pertinentes ao armazenamento e recuperação da informação. (LANCASTER, 2004, p. 20; 21, grifo do autor).

Silva e Fujita (2004) ressaltam semelhanças e diferenças entre indexação alfabética de assunto e catalogação de assunto.

A indexação alfabética de assunto está vinculada à determinação de cabeçalhos de assuntos e por isso é, em alguns casos, também denominada de catalogação de assuntos. Apesar das divergências sobre semelhanças e diferenças entre os termos, a indexação alfabética de assuntos e a catalogação de assuntos são equivalentes porque são resultados de um mesmo processo: a análise de assunto. (SILVA; FUJITA, 2004, p. 142)

Além disso, as referidas autoras afirmam que a distinção entre os dois processos está na utilização de diferentes linguagens documentárias e seus resultados: lista de cabeçalho de assunto para catalogação de assunto e tesauros para indexação, os dois processos terão como produto final, respectivamente, o índice e o catálogo de assunto. Para Naves (2002) o termo indexação possui dois sentidos. O primeiro, mais amplo, refere-se à atividade de criação de índices, sejam de autor, de título, de assunto; de publicações (livros, periódicos) ou de catálogos ou bancos de dados; e sejam em bibliotecas ou centros de informações. O outro sentido, mais restrito, refere-se à indexação, classificação ou a catalogação dos assuntos das informações existentes em um acervo documental.

Segundo Robredo (2005), a representação temática se dá em duas direções: a localização de assuntos em diversos tipos de documentos (indexação) e/ou a localização física dos próprios documentos que contém a informação procurada (classificação). O referido autor não trata especificamente da catalogação de assunto 
juntamente com a indexação e a classificação, porém, para ele os conceitos da indexação, catalogação e classificação quando associados e auxiliados pela tecnologia, promovem uma profunda revolução conceitual, operacional e prática.

De acordo com Dias e Naves (2007) a catalogação visa criar representações dos documentos descrevendo tanto os aspectos físicos (catalogação descritiva) quanto os aspectos de conteúdo (catalogação por assunto). Além disso, consideram que o termo catalogação é o mais usual para descrever esse trabalho quando realizado no contexto da biblioteca.

A esse respeito, Foskett (1996) afirma que os livros são catalogados enquanto outros itens são indexados, e apresenta semelhanças e diferenças entre os dois processos:

- semelhanças: ambas as práticas têm os mesmos objetivos gerais identificar o item e fornecer acesso a ele por meio de várias abordagens, incluindo o assunto;

- diferenças: na catalogação do livro, o seu conteúdo é tratado no todo e os assuntos são fornecidos em uma escala limitada (um número de classificação para arranjo nas estantes e um ou dois cabeçalhos de assunto para acesso por meio do catálogo). Já na indexação de outros materiais a tendência é o detalhamento, em que há maior generosidade no fornecimento de termos para o acesso por assunto.

Realmente o termo catalogação deriva de catálogo. Porém, como bem ressalta Silveira (2007), é importante lembrar que o catálogo não se constitui apenas das partes identificadas nos códigos de descrição bibliográfica e ponto de acesso, mas também de assuntos de um documento.

Nesse sentido, segundo Silveira (2007) a catalogação de assunto passou a ser designada como representação temática, enquanto a catalogação descritiva referente à descrição bibliográfica e aos pontos de acesso passou a ser nomeada como representação descritiva. 
A indexação é entendida pelos autores Dias e Naves (2007) como o trabalho de organização da informação em contexto de serviços de indexação e resumos com o objetivo de organizar informações, principalmente, referentes a artigos de periódicos. Os referidos autores ressaltam que, normalmente, esse tipo de serviço não é feito por bibliotecas.

Dias e Naves (2007) revelam que há uma tendência em considerar a indexação e catalogação de assunto, além da classificação, como uma única atividade, uma vez reconhecida a existência das etapas de identificação de assunto e tradução dos mesmos para uma linguagem de tesauros, listas de cabeçalhos de assunto e classificação. Dessa forma, a variação terminológica acaba gerando confusão e incongruência.

No nosso ponto de vista, entendemos que a indexação é um processo inerente aos grandes sistemas de informação produtores de bases de dados que possuem índices construídos por meio daquele processo. Já a catalogação de assunto nos remete ao conceito de produção de catálogos em bibliotecas onde os documentos são armazenados e recuperados.

Com base nessas considerações, observamos que as divergências entre a indexação e a catalogação de assunto ficam claras quando autores como Milstead (1983), Fiúza (1985), Lancaster (2004), Silva e Fujita (2004), Robredo (2005), Dias e Naves (2007) reconhecem a indexação e a catalogação de assuntos como conceitualmente equivalentes. Essa situação pode ser explicada pelo desenvolvimento de cada um dos processos no decorrer do tempo fazendo com que surgissem várias concepções para os termos. A catalogação de assuntos está essencialmente ligada à construção de catálogos de bibliotecas e a indexação à construção de índices de bibliografias em serviços de informação que produzem bases de dados.

Essas diferenças residem principalmente no fato de que a catalogação na biblioteca apresenta um conjunto de princípios firmados e reconhecidos mundialmente que fornecem padrões para a elaboração de registros bibliográficos contribuindo para a construção da área da catalogação e para o intercâmbio de informações. Os serviços de indexação e resumo, por sua vez, não têm essa característica de universalidade, e 
apresentam diferenças entre seus métodos para descrição e pontos de acesso e diferentes padrões.

Além disso, devem ser considerados os objetivos e funções de um catálogo e de uma base de dados; a estrutura e conteúdo de um registro bibliográfico do catálogo e da base de dados e a escolha e as formas de pontos de acesso.

Segundo Fattahi (1998), a catalogação poderia apreender alguns princípios dos serviços de indexação e resumos tais como pontos de acesso adicionais de autor. O referido autor afirma que a uniformidade e a consistência são requisitos básicos para o controle e o acesso bibliográfico efetivo no ambiente global on-line e que a tendência crescente na integração, fusão e disponibilização de diferentes registros bibliográficos revela uma forte afirmação dos valores de consistência entre os diferentes tipos de bases de dados, o que ajudará o usuário a buscar de maneira mais fácil e eficiente entre a extensa gama bibliográfica.

\section{CONSTRUÇÃO DE CATÁLOGOS COLETIVOS EM BIBLIOTECAS UNIVERSITÁRIAS: CONTRIBUIÇÕES DA POLÍTICA DE INDEXAÇÃO}

Considerando que a política de indexação influencia a catalogação de assunto e contribui para a elaboração de catálogos coletivos em bibliotecas universitárias, apresentaremos aspectos relativos ao processo de catalogação cooperativa e seu produto final, o catálogo, inserido no contexto universitário da biblioteca acadêmica.

A biblioteca universitária insere-se em um contexto cujos objetivos maiores são o desenvolvimento educacional, social, político e econômico da sociedade.

Para Fujita (2005) são funções da biblioteca universitária: armazenagem, organização e acesso. Ainda segundo a referida autora, essas três funções estão presentes em toda a evolução do processo de socialização do conhecimento realizado pela universidade ao longo do tempo, ainda que se considere a permanente mudança dos formatos documentários para registro do conhecimento e seu modo de acesso, como por exemplo, os catálogos.

(c) Revista Digital de Biblioteconomia e Ciência da Informação,Campinas, v.7, n. 2, p. 118-150, jan./jun. 2010- ISSN: 1678-765X. 
No que diz respeito especificamente à catalogação, Cunha (2000) afirma que a catalogação original não desaparecerá, mas ficará restrita a grandes bibliotecas que fornecerão os dados bibliográficos e catalográficos dos recursos informacionais para downloading. Além disso, afirma também que “A política de indexação seguida pela biblioteca é que irá delinear quais níveis de representação da informação serão adotadas em um determinado acervo.” (CUNHA, 2000, p. 81).

O fornecimento de “cópias” dos dados catalográficos sobre os recursos informacionais de uma biblioteca para outra é um dos procedimentos inerentes à catalogação cooperativa. Vílchez Pardo (2002) descreve a catalogação cooperativa como sendo resultado de importação de registros bibliográficos de diversas bibliotecas resultando em um catálogo cooperativo que apresenta os registros bibliográficos e suas respectivas localizações nas bibliotecas.

A catalogação cooperativa teve seu início quando a Library of Congress (LC) passou a comercializar suas fichas catalográficas impressas. Desse modo, não era mais necessária a elaboração de novas fichas pelas bibliotecas e sim somente determinar o cabeçalho de assunto, também sugeridos pela LC, e incorporar as fichas ao catálogo da biblioteca que comprou a ficha catalográfica.

Sobre os catálogos cooperativos, Umpierre, Favaretto e Silva (2006) consideram que a concepção de um catálogo cooperativo aumentará a capacidade de acesso à informação pela comunidade acadêmica, possibilitando a utilização de uma ferramenta que poderá oferecer interfaces de busca mais flexíveis, trazendo maior visibilidade sobre os acervos coletivos das bibliotecas universitárias. Segundo esses autores, a concepção dos catálogos cooperativos automatizados tornou possível a migração de informações contidas em fichas impressas para o meio eletrônico. A esse processo de migração denominamos conversão retrospectiva (retrospective conversion - RECON) que consiste no aproveitamento de registros já prontos e existentes em outras bases de dados e servem como fontes de dados bibliográficos e catalográficos, diminuindo o tempo e os esforços do catalogador durante a catalogação. Portanto, consideramos que a política de indexação pode ser importante instrumento para auxiliar a formação de um catálogo de qualidade.

(C) Revista Digital de Biblioteconomia e Ciência da Informação,Campinas, v.7, n. 2, p. 118-150, jan./jun. 2010- ISSN: 1678-765X. 
$\mathrm{Na}$ biblioteca, os tratamentos de forma e conteúdo, embora operacionalmente diferentes, são dependentes um do outro. O formato descritivo utilizado é o catalográfico, a maioria em MAchine Readable Cataloging 21 (MARC21), que conterá o resultado das operações de tratamento de forma - autor, título, edição, casa publicadora, data, número de páginas etc.- e de conteúdo documentário -o número de classificação, obtido pela classificação, os cabeçalhos de assuntos determinados pela indexação e, em alguns casos, o resumo derivado da elaboração de resumo.

Fernández Molina e Moya Anegón (1998) afirmam que, tradicionalmente, os catálogos das bibliotecas têm proporcionado possibilidades limitadas para as buscas por assunto, concentrando a maior parte dos esforços na catalogação descritiva e lembram que se a intenção era economizar tempo podiam ter feito isso na catalogação descritiva e não temática.

Reforçando o aspecto da simplificação do processo de catalogação de assunto que o reduziu a uma operação de “cópia”, Connell (1996) afirma que, ironicamente, o uso dos registros bibliográficos como principal fonte de catalogação tem exacerbado esse problema. Essa situação deve-se ao fato de que a catalogação cooperativa fornece a descrição básica do que é publicado e está nas coleções de bibliotecas, porém, muitos elementos estruturais do catálogo não podem ser obtidos de forma “pré-empacotada”, pois a estrutura do catálogo (e conseqüentemente do registro bibliográfico) depende da coleção e comunidade local e esforços devem ser envidados para fazer a conexão entre os usuários e os assuntos utilizados.

Com a Internet, os catálogos, por sua vez, adquirem caráter público e podem ser acessados on-line, dando origem ao Online Public Access Catalog (OPAC), o que requer qualidade de apresentação dos registros que agora podem ser visualizados mundialmente.

Olson e Boll (2001) apresentam a premissa de que o acesso por assunto em catálogos online é um processo complexo que envolve a interação entre os seguintes componentes: base de dados do catálogo on-line, as linguagens utilizadas para análise de assunto, os usuários, o hardware e o software que permitirão ao usuário interagir com o catálogo.

(c) Revista Digital de Biblioteconomia e Ciência da Informação,Campinas, v.7, n. 2, p. 118-150, jan./jun. 2010- ISSN: 1678-765X. 
Todos esses componentes formarão o sistema de acesso por assunto e determinarão o sucesso da recuperação da informação.

A esse respeito, Cunha (2000) manifesta sua concordância quando afirma que o desenvolvimento das bibliotecas universitárias depende do intercâmbio de experiências sobre os projetos em andamento, da formação de consórcios para compra de hardware e software e da definição de um padrão mínimo entre os sistemas utilizados.

Ainda nesse sentido, Fujita, Rubi e Boccato (2009, p. 3) esclarecem que a visibilidade assumida pelo catálogo devido à Internet aumenta a responsabilidade do bibliotecário fazendo com que seja necessária uma mudança de postura desse profissional, o que exige a adoção de critérios de qualidade para a indexação, sendo a política de indexação um deles.

Além disso, as referidas autoras afirma que

A política de indexação torna-se importante porque visa à gestão da informação registrada de modo a dar visibilidade na recuperação, além de identificar condutas teóricas e práticas das equipes de tratamento da informação documentária envolvidas para definir um padrão de cultura organizacional coerente com a demanda da comunidade acadêmica interna e externa. Nesse sentido, é procedente a observação quanto ao nível de influência da interação sociocognitiva dos profissionais com o contexto de tratamento da informação documentária na tarefa de indexação. (FUJITA; RUBI; BOCCATO, 2009, p. 3)

Ressaltamos que os estudos sobre política de indexação, leitura documentária e tratamento temático da informação com a utilização de técnica introspectiva de coleta de dados qualitativos para observação do contexto sociocognitivo de bibliotecários catalogadores e indexadores vêm sendo desenvolvidos de maneira inédita no Brasil pelo grupo de Pesquisa Análise Documentária, liderado pela Profa. Dra. Mariângela Spotti Lopes Fujita.

A indexação é reconhecidamente um processo imbuído de subjetividade, uma vez que é realizado por seres humanos que usam seu conhecimento prévio da linguagem do 
sistema, da estrutura textual, do assunto e até de mundo, acionam estratégias durante a leitura documentária a fim de que seu objetivo seja atingido: identificação e seleção de conceitos de um documento. Para que a subjetividade seja minimizada e os termos identificados sejam os que melhor representem o documento, cada uma das etapas citadas decompõe-se em um passo-a-passo amplamente estudado e divulgado na literatura e em normas nacional e internacional.

Lancaster (2004) afirma, no entanto, que o processo de indexação parece ser refratário a regras, destacando que não foram desenvolvidas regras verdadeiras para atribuição de termos o que dificultaria o trabalho prático do profissional indexador.

Com base em nossos estudos (RUBI, 2003; FUJITA, RUBI, BOCCATO, 2009), podemos afirmar que a política de indexação torna-se uma importante aliada para que o bibliotecário realize seu trabalho e maneira mais racional e objetiva.

Consideramos que a política de indexação é pertinente não somente aos objetivos específicos da indexação, como também às decisões administrativas que devem refletir a filosofia da biblioteca em questão. Sobre esse aspecto administrativo, Carneiro (1985) apresenta requisitos imprescindíveis ao planejamento de um sistema de recuperação de informação ao se estabelecer uma política: identificação do contexto, da clientela e a disponibilidade de recursos relativos a infra-estrutura.

Fujita (2003) afirma que a política de indexação está inserida em dois contextos complementares:

a ) sociocognitivo do indexador: a política de indexação, as regras e procedimentos do manual de indexação, a linguagem documentária para representação e mediação da linguagem do usuário e os interesses de busca dos usuários;

b) físico de trabalho do indexador e dos gerentes - o sistema de informação.

De maneira geral, a literatura sobre política de indexação se mostra escassa. No âmbito nacional, destaca-se o clássico artigo de Carneiro (1985) que sinaliza para os seguintes elementos a serem considerados na elaboração de uma política de indexação: Cobertura de assuntos; Seleção e aquisição dos documentos-fonte; Processo de indexação (Nível de exaustividade; Nível de especificidade; Escolha da linguagem; 
Capacidade de revocação e precisão do sistema); Estratégia de busca; Tempo de resposta do sistema; Forma de saída; Avaliação do sistema.

Em âmbito internacional, podemos destacar o trabalho do espanhol Cubillo (2000) que trata das mudanças e continuidades das organizações de gestão do conhecimento, apontando o tratamento documentário como uma dimensão estratégica que deve valorizar o trabalho do autor do documento e destaca que esse documento constitui o representante ou substituto das idéias (surrogate of knowledge) do próprio autor.Igualmente, assinala a importância e a urgência da implantação de política de indexação.

Para Foskett (1973) três aspectos devem ser complementares ao estudo sobre política de indexação. São eles: capacidade de consulta aleatória; garantia literária; formação do indexador.

Olson e Boll (2001) afirmam que, no processo de indexação, as chances de uma melhor correspondência entre a indexação e a questão de busca do usuário dependem de fatores, que em nosso entendimento, dizem respeito a decisões tomadas para a consolidação de elementos para uma política de indexação:

1 Adequação: habilidade do indexador em determinar o assunto do documento e traduzi-lo adequadamente para o vocabulário controlado;

2 Exaustividade: o número de conceitos representados no registro bibliográfico; está condicionado ao estágio de análise de assunto.

3 Especificidade: relacionado à fase de tradução do conceito para o vocabulário controlado, diz respeito ao nível hierárquico da representação do assunto. Está dividido em três fatores: a especificidade e a co-extensividade do vocabulário; a especificidade de sua aplicação e a especificidade do termo no contexto da indexação.

4 Consistência: diz respeito aos itens sobre um mesmo assunto serem analisados conceitualmente e traduzidos da mesma maneira. São fatores que afetam a consistência: número de conceitos representados e o tamanho do vocabulário utilizado. 
As definições sobre especificidade e exaustividade e as implicações desses elementos no processo de indexação remetem aos princípios básicos elaborados por Cutter (1904) dentro do conjunto de regras para construção e arranjo de cabeçalhos de assunto: do uso, da entrada específica e da estrutura sindética.

Pelo princípio do uso, as descrições devem ser feitas da forma usada pelo usuário. O princípio da entrada específica esclarece que os assuntos devem dar entrada pelo termo mais específico e pela não pela classe a que estão subordinados. O princípio da estrutura sindética estabelece mecanismos para o relacionamento de cabeçalhos, permitindo as ligações de assuntos correlacionados através de uma rede de referências cruzadas (relação de equivalência, hierárquica e associativa). Esses princípios influenciaram Ranganathan na elaboração das 5 Leis da Biblioteconomia.

Nesse sentido, acreditamos que os princípios de Cutter (1904) e as leis de Ranganathan (1931) podem ser considerados como indícios primários de uma política de indexação, uma vez que se referiam:

- ao modo como deveriam ser as entradas dos assuntos pelos termos determinados (princípio da entrada específica);

- à indicação das relações associativas, de equivalência e hierárquicas entre os termos (princípio da estrutura sindética);

- sobre a necessidade dos usuários no momento da descrição dos assuntos (princípio do uso).

O que nos chama a atenção é que esses princípios foram elaborados de modo a subsidiar a construção de catálogos em contexto de bibliotecas e, atualmente, estão sendo mais utilizados em contexto de sistemas de informação especializados e/ou produtores de bases de dados do que nas próprias bibliotecas. Dessa maneira, consideramos que os princípios de Cutter (1904) e de Ranganathan (1931) continuam atuais e precisam ser considerados na elaboração da política de indexação em contexto de bibliotecas.

Além dos elementos de política de indexação já conhecidos e divulgados na literatura, o artigo de Moen e Benardino (2003) nos chama a atenção quando apresenta um interessante estudo relacionando a política de indexação com o MAchine Readable 
Cataloging (MARC), formato utilizado para descrição bibliográfica que possibilita não só a automação das bibliotecas, como o intercâmbio de registros bibliográficos legíveis por máquina. Os autores esclarecem que a política de indexação deve também delinear os campos e sub/campos do formato MARC efetivamente utilizados na construção do catálogo e na recuperação da informação.

Vílchez Pardo (2002) apresenta uma publicação espanhola intitulada Lista de encabezamiento de materia para bibliotecas públicas em que são apresentados princípios para determinação de cabeçalhos de assunto. São eles:

- Especificidade: o cabeçalho designa um único assunto;

- Síntese: o conteúdo expresso com a maior simplicidade possível;

- Uso: não perder de vista o usuário, a coleção etc.

- Lingüístico: linguagem acessível e na ordem normal do idioma;

- Uniformidade: para cada assunto haverá um cabeçalho uniforme, destacar os casos de homonímia;

- Economia: não determinar vários cabeçalhos de assunto a um único documento. Em caso de biblioteca pública, determinar um assunto mais geral.

A Biblioteca Nacional da França afirma em seu site (http://www.bnf.fr) que sua política de indexação é parte de sua política de catalogação, considerando-a como essencial para garantir a homogeneidade dos registros bibliográficos de todos os tipos de documentos da biblioteca.

O exemplo da Biblioteca Nacional da França é compatível com nossa visão sobre a diferenciação entre os processos de indexação e de catalogação, sobre a necessidade de elaboração de política de indexação para construção de catálogos e sobre a postura adotada pelo profissional, que neste caso é nomeado como catalogador, com relação às decisões referentes ao processo de indexação.

Em 2007, no $73^{\circ}$ Congresso da International Federation of Library Associations and Institutions (IFLA) realizado em Durban (África do Sul), o grupo de trabalho sobre Diretrizes para Acesso por Assunto das Agências Bibliográficas Nacionais (Working Group on Guidelines for Subject Access by National Bibliographic Agencies) afirmou que considera

(c) Revista Digital de Biblioteconomia e Ciência da Informação,Campinas, v.7, n. 2, p. 118-150, jan./jun. 2010- ISSN: 1678-765X. 
[...] o desenvolvimento de uma política de indexação/catalogação um passo necessário para oferecer aos usuários uma informação adequada sobre o tipo disponível de acesso por assunto para os documentos listados em bibliografias nacionais. O objetivo do grupo é fazer recomendações às bibliotecas nacionais sobre os tipos de documentos que serão indexados de acordo com as necessidades de vários grupos de usuários. (BOURDON; LANDRY, 2007, p. 2, tradução nossa).

Observa-se a partir do documento elaborado por esse grupo de trabalho e das expectativas para o delineamento de uma diretriz para bibliotecas e agências de bibliografias nacionais que há uma volta à teoria da indexação/catalogação de assunto e dos estudos ressaltando a importância da elaboração de sua política não mais somente direcionada aos grandes sistemas de informação especializados, mas também às bibliotecas nacionais.

Villén-Rueda (2006) faz importante relação entre a política de indexação e os catálogos ao afirmar que para melhorá-los são necessários desenvolvimentos específicos de política de indexação comuns e coerentes, de acordo com o contexto automatizado.

Consideramos ser necessário que as bibliotecas percebam a importância da indexação em todo o ciclo documentário, considerando-a como parte da administração, compreendendo que esse processo necessita de parâmetros que guiem os indexadores nos momentos de tomada de decisões, minimizando subjetividade e incertezas durante o processo de catalogação de assunto, reconhecendo, portanto, a importância de se implantar uma política de indexação.

Nesse sentido, a metodologia introspectiva de coleta de dados qualitativos- Protocolo Verbal - serve para demonstrar a visão sociocognitiva da atuação do profissional sobre a política de indexação na catalogação de assunto.

\section{METODOLOGIA}

A metodologia utilizada constituiu-se de estudo diagnóstico composto por duas partes:

a) estudo do funcionamento e procedimentos do tratamento de informações documentárias na Rede de Bibliotecas da Universidade Estadual Paulista (UNESP) na 
perspectiva da Coordenadoria Geral de Bibliotecas (CGB); b) estudo do funcionamento e procedimentos do tratamento de informações na Rede de Bibliotecas da UNESP na perspectiva do catalogador.

No contexto da Rede de Bibliotecas da UNESP, os bibliotecários indexadores correspondem aos bibliotecários catalogadores que desenvolvem as atividades de catalogação e indexação.

Para a realização da primeira parte, foram aplicados questionários de diagnóstico organizacional aos diretores das bibliotecas universitárias A elaboração do questionário foi fundamentada no diagnóstico organizacional exposto por Almeida (2005, p. 53-55) para identificar itens organizacionais, materiais, de procedimentos e processos, documentários e de pessoas que constituem o contexto sociocognitivo do catalogador. São elas: Espaço físico; área(s) de especialidade(s) da biblioteca; Estrutura organizacional da biblioteca; Tipo de gestão; Atividades de planejamento; Desenvolvimento de projetos; Documentação técnica e administrativa; Pessoal e programas de capacitação; Acervo e processamento técnico; Informatização; Recuperação da Informação; Usuários e programas de orientação; Comunicação e divulgação; Relações com instituições afins e Avaliação.

A segunda parte, sobre o funcionamento e procedimentos do tratamento de informações na Rede de Bibliotecas da UNESP na perspectiva do catalogador, utilizou a técnica introspectiva do protocolo verbal nas seguintes modalidades:

1. Protocolo verbal individual (PVI) realizado com bibliotecários catalogadores para identificação dos procedimentos de análise de assunto na catalogação de livros, bem como dificuldades e restrições;

2. Protocolo verbal em grupo (PVG) com bibliotecários chefes, bibliotecários catalogadores, bibliotecários de referência, usuários docentes pesquisadores, líderes de grupos de pesquisa, e usuários discentes de graduação e pós-graduação para acesso ao conhecimento das pessoas que participam do contexto de tratamento de conteúdos documentários de bibliotecas universitárias como fonte de coleta de dados qualificada do diagnóstico.

(c) Revista Digital de Biblioteconomia e Ciência da Informação,Campinas, v.7, n. 2, p. 118-150, jan./jun. 2010- ISSN: 1678-765X. 
As coletas de dados foram realizadas em uma amostra de 9 bibliotecas da UNESP das três áreas do conhecimento - Humanas, Exatas e Biológicas - respectivamente, Pedagogia, Engenharia Civil e Odontologia, cujas transcrições geraram uma grande massa de dados. Considerando a abordagem sociocognitiva na interação do ambiente (biblioteca) e das diferentes perspectivas oriundas dos diferentes sujeitos participantes das coletas (bibliotecários chefes, de referência, catalogadores e usuários discentes e docentes) observamos a complexidade que envolveria a análise dessas transcrições.

Destacamos que o foco da análise foi o protocolo verbal em grupo, pois acreditamos que ele trouxe evidências da visão geral do contexto em que a política de indexação é elaborada e colocada em prática na biblioteca, quer seja na parte gerencial quer seja na de tratamento da informação, evidenciando ser elemento norteador dos procedimentos realizados pelos indexadores. Dessa forma, os protocolos verbais individuais serviram para complementar as constatações feitas a partir dos protocolos verbais em grupo.

A técnica do Protocolo Verbal é uma metodologia qualitativa de coleta de dados introspectivos que consiste na gravação da exteriorização verbal do pensamento de um ou mais indivíduos durante a realização de uma tarefa. O "Pensar alto" do sujeito é gravado e transcrito literalmente. No caso do leitor, ele pode exteriorizar seus processos mentais enquanto a informação processada está sob o foco de sua atenção. Ele lê e interpreta ao mesmo tempo, exteriorizando em voz alta tudo o que "passa pela sua cabeça” durante a leitura.

O protocolo verbal em grupo consiste na reunião de pessoas (sujeitos participantes e pesquisador) para a leitura de um texto e discussão de temas suscitados pelo mesmo. Nesse caso, o pesquisador interage como um dos sujeitos participantes com uma única função a mais, controlar o gravador.

Ambos os protocolos verbais seguem procedimentos semelhantes para sua aplicação:

\section{A) Procedimentos anteriores à coleta de dados}

\section{Definição do universo da pesquisa:}

PVG e PVI: bibliotecas universitárias da Rede de Bibliotecas UNESP;

\section{Seleção do Texto-Base:}

(c) Revista Digital de Biblioteconomia e Ciência da Informação,Campinas, v.7, n. 2, p. 118-150, jan.jjun. 2010- ISSN: 1678-765X. 
PVG: trecho entre as páginas 205 e 208 do seguinte artigo: DIAS, Eduardo

Wense; NAVES, Madalena Martins Lopes; MOURA, Maria Aparecida. O usuário-pesquisador e a análise de assunto. Perspectivas em Ciência da Informação, Belo Horizonte, v. 6, n. 2, p. 205-221, jul./dez. 2001.

PVI: o próprio registro bibliográfico a ser catalogado para compor o catálogo base de dados Athena - da Rede de Bibliotecas da UNESP;

\section{Definição da tarefa:}

PVG: discussão do texto-base previamente referenciado

PVI: foi solicitado aos catalogadores que realizassem a catalogação dos registros bibliográficos em suas três variações: item considerado original (Catalogação Original - CO), registro aproveitável (RA) e o registro idêntico (Identidade Total - IT);

\section{Seleção dos Sujeitos:}

PVG: 3 bibliotecários (chefe, catalogador e de referência), 1 docente e 1 discente.

PVI: população de bibliotecários catalogadores representativa das três áreas do conhecimento - Humanas, Exatas e Biológicas - respectivamente, Letras, Matemática e Odontologia em nove bibliotecas da UNESP;

\section{Conversa informal com os sujeitos:}

Nesta conversa, as pesquisadoras fizeram contato com os sujeitos por intermédio da Coordenadoria Geral de Bibliotecas explicando os objetivos da pesquisa, a metodologia utilizada e agendando o dia para a coleta de dados. Todos os participantes tiveram suas identidades preservadas.

B) Procedimentos durante a coleta de dados

PVG: após a leitura do texto-base, iniciou-se a discussão, em que o pesquisador fez as intervenções necessárias de modo a instigar os participantes. Toda a discussão foi gravada e transcrita na íntegra.

PVI: toda a exteriorização do pensamento feita pelo catalogador durante a execução da tarefa de catalogação foi gravada com o auxílio de um MPEG Audio Layer - 3 (MP3) player;

C) Procedimentos posteriores à coleta de dados

Transcrição das gravações:

(c) Revista Digital de Biblioteconomia e Ciência da Informação,Campinas, v.7, n. 2, p. 118-150, jan.jjun. 2010- ISSN: 1678-765X. 
PVG: após a gravação da discussão do texto pelos sujeitos, foi feita a transcrição literal com a identificação das fontes das falas individuais. Essa identificação foi feita da seguinte forma: Bibliotecário-Chefe; Bibliotecário de Referência; Bibliotecário Catalogador; Docente; Aluno; Pesquisador;

PVI: após a gravação do “pensar alto” durante a catalogação, foi feita a transcrição literal das gravações das falas dos sujeitos.

\section{Análise das transcrições:}

Com a transcrição pronta, foi feita uma leitura detalhada dos dados em busca de fenômenos significativos e recorrentes para construir categorias de análise que permitissem a análise dos dados de forma organizada e eficiente. Posteriormente à construção das categorias, voltou-se aos dados para retirar trechos da transcrição que exemplifiquem cada categoria.

As categorias para análise dos dados foram elaboradas a partir do referencial teórico sobre política de indexação. Com o objetivo de reunir as categorias e manter uma seqüência lógica para as análises, as categorias foram agrupadas nos seguintes eixos temáticos: Indexação (Capacidade de revocação e precisão do sistema, Especificidade, Exaustividade, Formação do indexador, Procedimentos relacionados à indexação, Manual de indexação (elaboração/utilização); Linguagem de indexação (Escolha da linguagem, Consistência/ Uniformidade, Exatidão); Sistema de busca e recuperação por assunto (Avaliação, Campos de assunto do formato MARC, Capacidade de consulta a esmo, Estratégia de busca, Forma de saída dos dados.

A título de ilustração, segue um exemplo da transcrição do Protocolo Verbal em Grupo:

\section{Categoria: Capacidade de revocação e precisão}

\section{PVG - Engenharia Civil - Bauru}

\section{Bibliotecário Chefe}

Mas, mesmo no campo de assunto local, a gente coloca o que a gente entende que seja. Então, nós temos três faculdades na área de Engenharia. Existe uma discrepância. Eu acredito que cada faculdade coloca de um jeito, então isso precisaria estar padronizado de uma outra forma para que todo mundo colocasse mais ou menos a mesma coisa. É uma opção, foi uma coisa que a gente até batalhou bastante para ter esse campo de assunto local por conta disso, mas que ainda não atende a todos, e isso gera uma dificuldade na hora da busca, porque você coloca no assunto geral. Tem uma coisa em "Engenharia Civil", muita coisa, então de repente o livro que você está catalogando, tem que olhar cem obras para saber se tem aquele assunto que te interessa. Vamos supor seja 
"Edificações", não estou falando que "Edificações" não seja padronizado, nem sei, mas vamos supor que não fosse.

\section{Docente}

"Ciências dos Materiais" por exemplo, está dentro da área de Engenharia Mecânica, dentro da Engenharia Civil, talvez na Engenharia Elétrica, não saberia dizer, mas na Engenharia de Produção também. E às vezes é uma dificuldade porque está lá nas Ciências ou está na Engenharia, está na Engenharia Mecânica ou na Civil. Um exemplo: eu começo sempre pelo assunto, a primeira tentativa é o assunto e daí eu vou tentando pelas palavras-chave, às vezes uma não me atende e às vezes a resposta vem por alguma coisa que eu não iria imaginar num primeiro momento.

\section{ANÁLISE DOS RESULTADOS E DISCUSSÃO}

Os resultados apresentados demonstram a visão do contexto em que a política de indexação está inserida. Assim, foram analisados os questionários de diagnóstico organizacional respondidos pelos diretores das bibliotecas universitárias e os dados qualitativos gerados pelas transcrições a partir dos protocolos verbais individuais e em grupo.

A análise dos questionários dos diagnósticos organizacionais revelou uma estrutura composta das seções de técnicas de referência e atendimento ao usuário e de processamento técnico. Pela análise do quantitativo de pessoal e distribuição de atividades das bibliotecas, observou-se que um mesmo bibliotecário realiza tanto a catalogação de forma quanto a de conteúdo. Enquanto que a referência e o atendimento ao usuário são serviços que contam com quantitativo superior de bibliotecários em relação à área do tratamento da informação documentária, denominadas, nas bibliotecas, de processamento técnico.

Em relação aos procedimentos para o tratamento documentário no fluxo informacional, a análise dos questionários de diagnóstico organizacional demonstrou que, de maneira geral, os procedimentos são realizados de modo semelhante entre as bibliotecas estudadas, mediante o uso de padrões para catalogação de forma (Anglo-American Cataloguing Rules 2nd. edition, Padrão UNESP de registros etc.) sem atender à especificidade do processo de análise de assunto em diferentes áreas do conhecimento. Para a atividade de análise de assunto para indexação, as bibliotecas da amostra não possuem documentação sobre elementos norteadores como um manual, ou mesmo outros documentos, que evidencie uma política de tratamento da informação documentária. 
Quanto à documentação específica para nortear as atividades do tratamento da informação documentária, no que se refere à análise de assunto para indexação, a gerência aponta a inexistência de manual de catalogação de assunto e reconhece as conseqüências disso, observando a necessidade de sistematização da atividade de catalogação de assunto e o catalogador sugere a elaboração e uso de manual para o bibliotecário catalogador.

Todas as bibliotecas participam dos programas de capacitação oferecidos pela CGB, porém, reconhecem que mais esforços poderiam ser feitos com relação à formação continuada desses profissionais, como a participação em cursos específicos de acordo com cada área de atuação do profissional bibliotecário.

A seguir, apresentamos os resultados das análises dos protocolos verbais a partir das categorias: Capacidade de revocação e precisão do sistema; Especificidade; Exaustividade; Formação do indexador; Procedimentos relacionados à indexação; Manual de indexação (elaboração/utilização); Escolha da linguagem; Consistência/ Uniformidade, Exatidão; Avaliação do sistema de busca; Campos de assunto do formato MARC; Capacidade de consulta a esmo; Estratégia de busca; Forma de saída dos dados.

- Capacidade de revocação e precisão: a alta revocação está ligada à baixa precisão dos termos designados para representar seus assuntos. Acreditamos que a biblioteca deva adotar o detalhamento e a exaustividade também para o tratamento temático de seus livros. Essa decisão política resultará em uma recuperação com níveis de revocação menor e com um índice maior de precisão, ou seja, mesmo sendo um número reduzido de documentos, são exatamente esses que correspondem às questões de busca do usuário. Além disso, consideramos que deva haver um equilíbrio entre o número de assuntos determinados e a especificidade desejada;

- Especificidade: um dos critérios para determinação do nível de especificidade dos assuntos dos documentos é a biblioteca onde esses documentos estão inseridos. A tendência geral entre as bibliotecas é representar o assunto dos documentos no nível mais geral, fazendo com que haja uma alta revocação, ou seja, a recuperação de um grande número de documentos. A decisão política que envolve a questão da 
especificidade está muito ligada à questão da revocação e precisão, que vimos na categoria anterior, e com a exaustividade, que veremos a seguir. Todas elas devem ser pensadas conjuntamente de modo a definir o perfil do catálogo da biblioteca, se ele será mais específico, garantindo uma maior precisão na recuperação, ou se ele será mais exaustivo aumentando a revocação do sistema;

- Exaustividade: não há uma decisão política sobre o número de termos designados para representar o assunto do documento. O limite é determinado pelo bibliotecário no momento da catalogação e dependerá dos assuntos abordados no documento e na sua comunidade usuária. Para evitar disparidades entre os bibliotecários e as bibliotecas, é necessária a elaboração de um manual de indexação que contemple todos os aspectos citados anteriormente e determine como eles serão trabalhados por todos da rede de bibliotecas;

- Formação do indexador: há uma preocupação da CGB em capacitar os catalogadores quanto à utilização do padrão UNESP para a catalogação. Não há um curso específico voltado para o processo de indexação, cuja aprendizagem é feita na prática do dia-a-dia durante o fazer bibliotecário com iniciativa do próprio profissional e com auxílio de especialistas nas áreas de assunto. Acreditamos que a mesma atenção dada ao tratamento descritivo, por meio de formação continuada e o desenvolvimento de um manual que contém os padrões a serem seguidos nesse tipo de representação, deva ser dispensada também ao tratamento temático dos documentos;

- Procedimentos relacionados à indexação: o bibliotecário segue o padrão da UNESP para catalogação, porém não há nada específico a respeito do procedimento de leitura documentária para determinação do termo. A política de indexação deve indicar e detalhar todos os procedimentos que devem ser realizados durante o processo de indexação, quais sejam: análise, síntese e representação. A descrição dos procedimentos permitirá que um padrão mínimo seja seguido por todas as bibliotecas da Rede, auxiliando os bibliotecários e atuando também como um instrumento de formação em serviço;

- Manual de indexação (elaboração/utilização): não há nenhuma iniciativa concreta em relação à elaboração de manuais de indexação. Os manuais utilizados são aqueles 
de serviço, como regimentos e regulamentos, e o padrão UNESP para catalogação, porém nenhum deles apresenta ao menos diretrizes sobre a representação de assunto. Deve ser uma decisão da UNESP, enquanto rede, elaborar um manual que contemple também a questão do tratamento temático da informação, no que diz respeito aos seus procedimentos, a sua filosofia e suas diretrizes, que possa guiar o bibliotecário durante seu serviço;

- Escolha da linguagem: Observamos que a linguagem documentária não atende as necessidades específicas da demanda da comunidade usuária, dificultando também o trabalho do bibliotecário. A decisão política sobre a escolha da linguagem deve levar em conta questões sobre sua manutenção, atualização, pertinência e especificidade de forma atender adequadamente os usuários da biblioteca;

- Consistência/uniformidade: há uma preocupação dos bibliotecários quanto à padronização dos termos utilizados para os mesmos documentos das mesmas áreas, caracterizando a Rede de Bibliotecas como tal. A política de indexação pode definir qual o nível de especificidade sobre o qual um documento será representado, tendo em vista, principalmente os cursos atendidos pela biblioteca;

- Adequação: existe esforço do bibliotecário no que diz respeito à representação exata do conteúdo do documento. A decisão sobre qual linguagem utilizar e em qual momento diminuiria as incoerências cometidas durante esse processo no que diz respeito à representação adequada do assunto do documento;

- Avaliação do sistema de busca: a ausência de um sistema de remissivas que remeta o usuário, no momento da busca, para a linguagem utilizada pelo sistema faz com que haja um certo "saudosismo” em relação às fichas catalográficas em papel. A utilização de um software para recuperação da informação em um catálogo on-line deve ser preocupação da política de indexação nas questões relativas à interface de busca que permita a organização da informação e a interatividade entre o usuário;

- Campos de assunto do formato MARC: mesmo havendo um campo (690) que deveria contemplar o termo utilizado pelo usuário que não está na linguagem, ou seja, livre, duas bibliotecas da área de Odontologia adotaram como decisão política o 
controle também desse campo utilizando uma linguagem documentária mais específica da área de saúde e que atende de forma mais adequada sua comunidade usuária. Uma decisão política poderia apresentar diretrizes gerais para a padronização e controle do campo 690, que poderia levar em consideração a utilização de uma linguagem documentária auxiliar específica de uma determinada área;

- Capacidade de consulta a esmo (browsing): há uma insatisfação por parte do usuário e do bibliotecário quanto à organização da informação que reflete no momento da recuperação da informação. Uma decisão política seria permitir a visualização da linguagem documentária adotada pelo sistema de recuperação da informação pelo usuário no momento da busca;

- Estratégia de busca: o tipo de busca mais realizada é por assunto, porém é aquela que mais traz dificuldade ao usuário. Quando isso ocorre, o usuário recorre ao bibliotecário para que o auxilie no uso das bases de dados, refinamento do assunto e tradução desse assunto nos termos de busca.. Uma forma de auxiliar o usuário e o bibliotecário no momento da recuperação da informação é a disponibilização da linguagem para que o usuário faça a consulta, verifique as opções do sistema de recuperação da informação e decida pelo termo que melhor represente sua necessidade de busca;

- Forma de saída dos dados: inicialmente, os catálogos automatizados coexistindo com os catálogos em fichas causavam resistência dos usuários quanto à sua utilização. Porém, a facilidade e a rapidez na recuperação da informação fizeram com que os usuários valorizassem as buscas pelo catálogo on-line. Para melhoria na recepção dos resultados de busca, apresentou-se como sugestão a separação dos itens bibliográficos de acordo com sua tipologia.

Esses resultados só foram possíveis devido à utilização da metodologia do protocolo verbal que permitiu a verificação do contexto de trabalho dos bibliotecários, da visão dos bibliotecários e usuários a respeito da política de indexação e dos procedimentos adotados durante a determinação dos assuntos dos documentos pelos bibliotecários. Além disso, permitiu que tivéssemos acesso ao dia-a-dia do fazer bibliotecário, bem como sua relação com seu contexto de trabalho e com os usuários e que 
conhecêssemos a linguagem utilizada pelos bibliotecários durante a realização de sua tarefa, em que ficou evidente a distância entre a teoria biblioteconômica e o fazer bibliotecário.

\section{CONSIDERAÇÕES FINAIS}

As bibliotecas universitárias assistem e assimilam as inovações tecnológicas, prova disso são seus catálogos que antes locais e restritos agora se tornaram disponíveis através da Internet, atravessando fronteiras geográficas, e funcionando como verdadeiras vitrines das bibliotecas.

Essa dimensão assumida pelo catálogo deve fazer com que o bibliotecário assuma uma nova responsabilidade pautada em compromisso com a construção de catálogos condizentes com a realidade não somente de sua comunidade usuária local, mas também de uma comunidade usuária potencial virtual, cada vez mais exigente.

Acreditamos que a política de indexação deva servir como subsídio para a organização do conhecimento no catálogo, atuando como guia para o bibliotecário no momento da determinação dos assuntos dos documentos descritos nesses registros. Além disso, garantiria a personalização do catálogo de cada instituição e a individualização da recepção da informação pelo usuário, uma vez que ele estaria contemplado por meio dos assuntos designados para representação dos documentos.

Consideramos, portanto, que o bibliotecário que faz a catalogação do documento deva ter consciência sobre a importância de sua atuação também na representação do assunto, assumindo atitude profissional semelhante a um indexador que trabalha na produção de bases de dados.

A metodologia do Protocolo Verbal nas duas modalidades utilizadas, enquanto abordagem metodológica sociocognitiva, tem como foco o sujeito que realiza uma determinada atividade e sua cognição em relação ao seu contexto de produção. O foco está no contexto de tratamento temático do bibliotecário catalogador constituído de objetivos da indexação, política de indexação, regras e procedimentos do manual de indexação, a linguagem para representação e mediação da linguagem do usuário e os 
interesses de busca do usuário. Tudo isso representa o contexto em que ele está inserido e que certamente o influenciará durante o processamento textual para os objetivos de indexação.

Acreditamos, portanto, que a política de indexação deve ser compreendida como uma decisão administrativa das bibliotecas universitárias representada por meio de uma filosofia que reflita os objetivos da biblioteca, identificando condutas teóricas e práticas das equipes envolvidas no tratamento da informação da biblioteca para definir um padrão de cultura organizacional coerente com a demanda da comunidade acadêmica interna e externa. Além disso, a política de indexação deve estar descrita e registrada em manuais de indexação para que possam ser constantemente avaliadas e modificadas, se preciso.

\section{REFERÊNCIAS}

ASSOCIAÇÃO BRASILEIRA DE NORMAS TÉCNICAS. NBR 12676: Métodos para análise de documentos - determinação de seus assuntos e seleção de termos de indexação. Rio de Janeiro, 1992.

BOURDON, F. LANDRY, P. Best practices for subject access to national bibliographies: interim report by the Working Group on Guidelines for Subject Access by National Bibliographies Agencies. Durban: IFLA, 2007. Disponível em: <http://www.ifla.org/IV/ifla73/papers/089-Bourdon_Landry-en.pdf>. Acesso em: 21 ago. 2007.

CARNEIRO, M. V. Diretrizes para uma política de indexação. Revista da Escola de Biblioteconomia da UFMG, Belo Horizonte, v. 14, n. 2, p. 221-241, set. 1985.

CHAUMIER, J. Indexação: conceito, etapas e instrumentos. Trad. José Augusto Chaves Guimarães. Revista Brasileira de Biblioteconomia e Documentação, São Paulo, v. 21, n.1/2, p. 63-79, jan./jun. 1988.

CONNELL, T. H. Subject Cataloging. In: SMITH, L. C.; CARTER, R. C (Ed.).

Technical services management, 1965-1990: a quarter century of change and a look to the future. New York: Haworth Press, 1996. p. 211-222.

CUBILLO, J. Cambio y continuidad en las organizaciones de gestión del conocimiento. DataGramaZero, Rio de Janeiro, v.1, n. 4 ago. 2000. Disponível em: <www.dgz.org.br>. Acesso em: 20 set. 2006.

CUNHA, M. B. da. Construindo o futuro: a biblioteca universitária brasileira em 2010.

Ciência da Informação, Brasília, v. 29, n. 1, p. 71-89, jan./abr. 2000.

(c) Revista Digital de Biblioteconomia e Ciência da Informação,Campinas, v.7, n. 2, p. 118-150, jan./jun. 2010- ISSN: 1678-765X. 
CUTTER, C. A. Rules for a dictionary catalog. 4. ed. Government Printing Office: Washington, 1904.

DIAS, E. W.; NAVES, M. M. L. Análise de assunto: teoria e prática. Brasília: Thesaurus, 2007.

FATTAHI, R. Library cataloguing and abstracting and indexing services: reconciliation of principles in the online environment? Library Review, Bradford, v. 47, n. 4, p. 211216, 1998.

FERNÁNDEZ MOLINA, J. C.; MOYA ANEGÓN, F. Los catálogos de acceso público em línea: el futuro de la recuperación de información bibliográfica. Málaga: Asociación Andaluzia de Bibliotecário, 1998.

FIÚZA, M. M. O ensino da "Catalogação de assunto”. Revista da Escola de Biblioteconomia da UFMG, Belo Horizonte, v. 14, n. 2, p. 257-269, set. 1985.

FOSKETT, A. C. A abordagem temática da informação. Tradução Antonio Agenor Briquet de Lemos. São Paulo: Polígono; Brasília: UnB, 1973.

FOSKETT, A. C. The subject approach to information. 5.ed. London: Library Association Publishing, 1996.

FUJITA, M. S. L. A leitura documentária do indexador: aspectos cognitivos e lingüísticos influentes na formação do leitor profissional. 2003. 321f. Tese (LivreDocência em Análise Documentária e Linguagens Documentárias Alfabéticas) Faculdade de Filosofia e Ciências, Universidade Estadual Paulista, Marília.

FUJITA, M. S. L. Aspectos evolutivos das bibliotecas universitárias em ambiente digital na perspectiva da Rede de Bibliotecas da UNESP. Informação \& Sociedade: estudos, João Pessoa, v. 15, n. 2, 2005. Disponível em:

$<$ http://www.informacaoesociedade.ufpb.br/pdf/IS1520504.pdf>. Acesso em: 22 mar. 2006.

FUJITA, M. S. L.; RUBI, M. P.; BOCCATO, V. R. C. O contexto sociocognitivo do catalogador em bibliotecas universitárias: perspectivas para uma política de tratamento da informação documentária. Datagramazero, Rio de Janeiro, v. 10, p. 1-24, 2009.

Disponível em: <wwww.dgz.org.br> . Acesso em: 26 jan. 2010.

GUINCHAT, C.; MENOU, M. Introdução geral às ciências e técnicas da informação e documentação. 2. ed. rev. aum. Brasília: MCT/CNPq/IBICT, 1994.

INTERNATIONAL ORGANIZATION FOR STANDARDIZATION. ISO 5693:1985: documentation: methods for examining documents, determining their subjects, and selecting indexing terms. Geneve, 1985.

LANCASTER, F.W. Indexação e resumos: teoria e prática. 2.ed. Brasília: Briquet de Lemos, 2004.

MILSTEAD, J. L. Indexing for subject cataloguers. Cataloging \& Classification Quarterly, v. 3, n. 4, p.37-44, 1983. 
MOEN, W. E; BENARDINO, P. Assessing metadata utilization: an analysis of MARC content designation use. In: DUBLIN CORE CONFERENCE: SUPPORTING COMMUNITIES OF DISCOURSE AND PRACTICE - METADATA RESEARCH AND APPLICATION. 2003, Seattle. Online Proceedings... Seattle: Information School of the University of Washington, 2003. Disponível em: <http://www.siderean.com/dc2003/502_Paper58.pdf>. Acesso em: 6 set. 2007.

NAVES, M. M. L. El trabajo de los indizadores: factores que afectan al análisis de contenido. Scire, Zaragoza, v. 8, n. 1, p. 119-130, jan./jun. 2002.

OLSON, H. A.; BOLL, J. Subject analysis in online catalogs. 2. ed. Englewood, CO: Libraries Unlimited, 2001.

PINTO MOLINA, M. Análisis documental: fundamentos y procedimientos. 2. ed. rev. aum. Madrid, Eudema, 1993.

RANGANATHAN, S. R. The five laws of library science. Madras: The Madras Library Association, 1931.

ROBREDO, J. Documentação de hoje e de amanhã: uma abordagem revisitada e contemporânea da Ciência da Informação e de suas aplicações biblioteconômicas, documentárias, arquivísticas e museológicas. 4. ed. rev. e ampl. Brasília: Edição de autor, 2005.

RUBI, M. P. Elementos de política de indexação em manuais de indexação de sistemas de informação especializados. Perspectivas em Ciência da Informação, Belo Horizonte, v. 8, n. 1, p. 66-77, jan./jun. 2003.

RUBI, M. P. Política de indexação para construção de catálogos coletivos em bibliotecas universitárias. 2008. 169f. Tese (Doutorado em Ciência da Informação) Faculdade de Filosofia e Ciências, Universidade Estadual Paulista, Marília, 2008.

SHAW, R. R. Documentation: complete cycle of information service. College \& Research Libraries, Chicago, v. 18, n. 6, p. 452-454, 1957.

SILVA, M. R.; FUJITA, M. S. L. A prática de indexação: análise da evolução de tendências teóricas e metodológicas. Transinformação, Campinas, v. 16, n. 2, p. 133161, maio/ago. 2004.

SILVEIRA, N. C. Análise do impacto dos Requisitos Funcionais para Registros Bibliográficos (FRBR) nos pontos de acesso de responsabilidade pessoal. 2007. 108f. Dissertação (Mestrado em Ciência da Informação) - Pontifícia Universidade Católica, Campinas, 2007.

UMPIERRE, A. G. G.; FAVARETTO, B.; SILVA, F. C. C. Catálogos virtuais das bibliotecas universitárias no Brasil: realidade e perspectivas para a criação de uma rede cooperativa nacional. Informação \& Sociedade: estudos, João Pessoa, v. 16, n. 1, p. 148-147, 2006. 
UNISIST. Princípios de indexação. Revista da Escola de Biblioteconomia da UFMG, Belo Horizonte, v.10, n.1, p. 83-94, mar. 1981.

VAN SLYPE, G. Lenguages de indización: concepción, contrucción y utilización en los sistemas documentales. Trad. Pedro Hípola e Félix de Moya. Madrid: Fundación Germán Sánchez Ruipérez, 1991.

VÍLCHEZ PARDO, J. Tratamiento y ubicación de la colección. In: ORERA ORERA, L. (Ed.). Manual de Biblioteconomía. Madrid: Síntesis, 2002. p. 113-136.

VILLÉN-RUEDA, L. Indización y recuperación por materias en los opacs de las bibliotecas españolas: ¿dos décadas de evaluación? El profesional de la información, Barcelona, v. 15, n. 2, p. 87-98, marzo/abr. 2006.

\section{Milena Polsinelli Rubi}

Doutora em Ciência da Informação pela Faculdade de Filosofia e Ciências, Universidade Estadual Paulista (UNESP). Graduada em Biblioteconomia pela UNESP e mestrado em Ciência da Informação também pela UNESP. milenarubi@ufscar.br

\section{Mariângela Spotti Lopes Fujita}

Doutora em Ciências da Comunicação pela Universidade de São Paulo. Realizou concurso de Livre Docência em Análise Documentária e Linguagens Documentária Alfabéticas pela Faculdade de Filosofia e Ciências da UNESP.goldstar@flash.tv.br

Recebido em: 06/07/2009

Aceito para publicação em: jul/2009 